\title{
¿Paleativo o Paliativo?
}

\section{Palleative or Palliative?}

\section{Alfredo Pinzón-Junca • Bogotá, D.C. (Colombia)}

Los errores gráficos derivados de la inadecuada pronunciación no son infrecuentes. Es el caso de la palabra «paleativo», usada por algunos en lugar de «paliativo».

En español existen dos verbos con similitud fonética, pero con significado muy diferente:

Palear: (De pala y -ear):

tr. Trabajar con pala.

Observación: No existe en nuestro idioma el adjetivo derivado paleativo.

Paliar: (Del latín tardío palliâre 'tapar', y este derivado del latín pallium 'manto', 'prenda de vestir exterior'):

1. tr. Mitigar la violencia de ciertas enfermedades.

2. tr. Mitigar, suavizar, atenuar una pena o disgusto, etc.

3. tr. Disculpar, justificar algo.

Por lo tanto, el único término derivado correcto es paliativo, así como las diferentes conjugaciones del verbo paliar, frecuentemente utilizados en medicina en situaciones de enfermedades graves o terminales.

Paliativo, -va: (Del latín medieval palliât(um) 'cubierto' + -iu-um/-am 'recubierto'; documentado con el significado actual desde el siglo XVI) [inglés: palliative]:

1. adj. Aplicado a una enfermedad, a un trastorno o a alguna de sus manifestaciones: que los mitiga, suaviza, alivia, atenúa o frena, pero sin aspirar a curarlos.

Observación: Se usa mucho en el ámbito del tratamiento del dolor y de los tumores malignos.

2. s.m. Remedio, medida o intervención de acción paliativa.

\section{Fuentes:}

- Diccionario de la Real Academia Española de la Lengua, disponible en: www.rae.es

- Real Academia Nacional de Medicina. Diccionario de Términos Médicos. Editorial Médica Panamericana. 2012

* Envíe sus inquietudes, sugerencias o comentarios a: contacto@actamedicacolombiana.com - alfpin@hotmail.com Dr. Alfredo Pinzón-Junca: Especialista en Medicina Interna y Psicoanálisis. Hospital Universitario de La Samaritana y Hospital Simón Bolívar. Coordinador del Consejo de Acreditación y Recertificación de la ACMI ${ }^{\circledR}$. Bogotá, D.C. (Colombia).

E-mail: alfpin@hotmail.com

Recibido: 18/VI/2019 Aceptado: 26/VI/2019 